\title{
Redocumentarização: inovação no tratamento dos documentos permanentes digitalizados
}

\author{
Hercules Pimenta Santos \\ Universidade Federal de Minas Gerais, Escola de Ciência da Informação, Belo Horizonte, MG, Brasil \\ herculessantos.ufmg@gmail.com
}

DOI: https://doi.org/10.26512/rici.v12.n3.2019.19113

Recebido/Recibido/Received: 2018-11-13

Aceitado/Aceptado/Accepted: 2019-06-06

Resumo: 0 presente texto deriva de um estudo maior, interdisciplinar, que buscou elucidar impactos encontrados no processo de consulta e organização do documento arquivístico de idade permanente, digitalizado. Processos de estudo na Espanha, como aplicados no Brasil, objetivaram a busca de contrastes e aproximações em relação aos procedimentos entre as duas tradições acadêmicas. Com fins exploratórios, colhemos depoimentos de arquivistas, documentalistas e historiadores, brasileiros e espanhóis. Os profissionais entrevistados foram definidos de forma intencional. Aqui, discorremos sobre o pouco conhecido e nada difundido processo de redocumentarização, apresentando seu emprego no contexto dos arquivos de idade permanente. Abarcando os fundamentos da Diplomática, da Arquivologia, da Gestão de Documentos e Tecnologias da Informação, entendemos que este processo fornece um conjunto de requisitos amplo, de modo a proporcionar uma melhor forma de disponibilização de acervos permanentes virtuais, seja por acesso remoto ou local. Apresentamos, ainda, um dos projetos que julgamos melhor se enquadrar nos fundamentos conceituais do nosso estudo, o Projeto Portal de Archivos Españoles, o PARES.

Palavras-chave: Arquivologia. Arquivo permanente. Digitalização de acervos. Historiografia.

\section{Redocumentarization: innovation in the treatment of digitized permanent documents}

Abstract: The present text derives from a larger and interdisciplinary study that sought to elucidate the impacts found in the process of consultation and organization of the archival document, digitized. Study processes in Spain, as applied in Brazil, aimed the search for contrasts and approximations in relation to the procedures between the two academic traditions. For exploratory purposes, we gather testimonies from archivists, documentarists and historians, Brazilians and Spaniards. The professionals interviewed were intentionally defined. Here, we discuss the little-known and not widespread "redocumentarization" process, presenting its use in the context of archives of permanent age. Covering the fundamentals of Diplomatics, Archival Science, Document Management and Information Technology, we understand that this process provides a broad set of requirements, to provide a better way of making permanent virtual collections available, either by remote or local access. We also present one of the projects that we think best fit within the conceptual foundations of our study, the Portal of Spanish Archives Project, PARES. Keywords: Archival Science. Digitization of collections. Historiography. Permanent file.

Redocumentarización: innovación en el tratamiento de los documentos permanentes digitalizados 
Resumen: El presente texto deriva de un estudio mayor, interdisciplinario, que buscó elucidar impactos encontrados en el proceso de consulta y organización del documento archivístico de edad permanente, digitalizado. Los procesos de estudio en España, como aplicados en Brasil, objetivaron la búsqueda de contrastes y aproximaciones en relación con los procedimientos entre las dos tradiciones académicas. Con fines exploratorios, cosechamos testimonios de archivistas, documentalistas e historiadores, brasileños y españoles. Los profesionales entrevistados fueron definidos de forma intencional. En el presente texto, presentamos sobre lo poco conocido y aún no difundido proceso de Redocumentarización, presentando su empleo en el contexto de los archivos de edad permanente. Abarcando los fundamentos de la Diplomática, de la Archivología, de la Gestión de Documentos y Tecnologías de la Información, entendemos que este proceso proporciona un conjunto de requisitos amplio, para proporcionar una mejor forma de disponer de acervos permanentes virtuales, sea por acceso remoto o local. Presentamos, además, uno de los proyectos que juzgamos mejor enmarcados en los fundamentos conceptuales de nuestro estudio, el Proyecto Portal de Archivos Españoles, el PARES.

Palabras-clave: Archivologia. Archivo permanente. Digitalización de colecciones. Historiografía.

\section{Introdução}

O presente texto deriva da pesquisa de doutorado concluída no ano de 2018: Impactos provenientes da Redocumentarização de acervos permanentes na pesquisa histórica (SANTOS, 2018). Naquela, empreendemos uma captação empírica de dados em conjunto com um aprofundado estudo teórico reflexivo, como forma de apoiar a identificação de impactos do processo de virtualização do documento de arquivo, especificamente o de idade permanente, no fazer historiográfico e na prática arquivística. Foram realizadas entrevistas com arquivistas, documentalistas e historiadores no Brasil e na Espanha. A análise dessas entrevistas nos permitiu classificar o que entendemos como dificuldades e vantagens encontradas no processo de consulta e organização do documento digitalizado que adquiriu a fase permanente de preservação.

Optamos por estudar experiências fora do Brasil, a partir do conhecimento de que na Europa os estudos de Documentação são fortes em alguns países, sobretudo na Espanha, congregando as ciências documentais. De tal modo, os processos de estudo, entrevistas e observação no exterior objetivaram a busca de contrastes e aproximações em relação aos métodos praticados pelas duas tradições acadêmicas: brasileira e espanhola.

No Brasil, os convites e as entrevistas ocorreram de forma presencial entre janeiro e setembro de 2016 na Universidade Federal de Minas Gerais: Escola de Ciência da Informação e Programa de Pós-graduação em História. Em relação aos entrevistados espanhóis, também de forma presencial, as entrevistas foram realizadas no período de maio a julho de 2017 na cidade de Madrid, na Espanha, com pesquisadores da Universidade Complutense de Madrid: Faculdade 
de Ciências da Documentação e Faculdade de Geografia e História ${ }^{1}$. O total de 26 entrevistados foi composto por 13 no Brasil e 13 na Espanha.

Obtivemos um estudo interdisciplinar que buscou elucidar impactos encontrados no processo de consulta e organização do documento arquivístico de idade permanente, digitalizado. Procuramos analisar formas de organização desta tipologia documental desenvolvidas na Espanha, em relação às unidades de informação brasileiras. Buscamos confirmar, com a pesquisa, que os acervos digitalizados trouxeram novos significados para a organização documental arquivística e o acesso a esta.

Em diferentes épocas históricas e de acordo com as condições materiais e de conhecimento alcançadas, as instituições especializadas adotaram diferentes técnicas para facilitar o acesso das pessoas às informações organizadas. O desenvolvimento de novas normas e a invenção de ferramentas compõem uma dialética muito específica entre os especialistas, com o mercado procurando novos nichos rentáveis. Os sucessos resultam de uma rápida absorção da parte dos usuários, que é facilitada pela natureza aberta da rede e por uma distribuição massiva de informações instantâneas. As estratégias econômicas levam ao questionamento das antigas classificações. Trata-se de uma nova modernidade (PÉDAUQUE, 2007) gerada não só pela evolução tecnológica introduzida pelo digital, mas também pelas mudanças sociais em termos das múltiplas dimensões do documento (forma, conteúdo e meio), bem como o movimento de suas mediações (PÉDAUQUE, 2006).

Para Salaün (2007b), cada lado das rotas do Atlântico busca restaurar suas ciências da informação com base em suas raízes históricas. A linguagem de tratamento do tema Redocumentarização não é a mesma. Para esse autor, resta aos pesquisadores em Ciência da Informação $(\mathrm{Cl})$ o desafio, com a ajuda de seus colegas em outras disciplinas, de se apropriar dos conhecimentos pertinentes ao primeiro grupo. Ou seja, Salaün estaria considerando o caráter extremamente inerente à interdisciplinaridade na Ciência da Informação e acreditamos que, provavelmente, pelo fato de a informação ser fundamento de todas as áreas do conhecimento. Nessa linha, apresentaremos nossas considerações, fruto do processo descrito de estudos e pesquisas, sobre esse conceito muito recente e ainda pouquíssimo divulgado pelo mundo, principalmente no Brasil. E, como notamos, do mesmo modo, pouco conhecido também na Espanha, apesar de sua larga tradição no processo de documentação.

\footnotetext{
${ }^{1}$ Grupos de pesquisa: Grupo de investigación figuración, representación e imágenes de la arquitectura del siglo XVIII al XXI; Historia de la cultura impresa en España; Proyecto S U+M A [universidad+museo]: historia del arte, educación y museos e Fuentes literarias para la historia de las mujeres en España.
} 


\section{Redocumentarização}

O conceito de documento nos dias de hoje é constantemente abalado pelas formas de produção e acesso, e com ele seus valores e suas práticas. Diante disso, a Entidade documento não mais aparece em situação tão confortável, como quando o texto e o papel eram quase sinônimos propiciando uma estabilidade que se verificava no início do século passado, quando da sistematização dos processos de documentarização.

Segundo Salaün (2007b) a Cl teria se iniciado a partir de um "movimento de documentarização, no momento em que a explosão de documentos levou à construção ou ao desenvolvimento de técnicas de gestão documentária: Biblioteconomia, documentação, arquivística, ciência administrativa". Documentarizar é o termo que Salaün prefere, ao de Documentar, referindo-se a este como o tratamento do documento em suas fases tradicionais, como "catalogar, classificar, resumir [...] com vistas a otimizar o uso do documento permitindo um melhor acesso a seu conteúdo assim como uma melhor contextualização" (SALAÜN, 2007b, p. 3).

Esse processo foi baseado em uma ordem documentária com o advento do impresso, sistematizado a partir da virada do século XIX pelas regras de normalização, descrição e classificação de bibliotecários a arquivistas com conhecimento administrativo. Ao longo do século passado, mas caminhando para os dias atuais, o esforço foi continuado e ampliado com a evolução das técnicas de impressão. O objetivo da documentarização seria otimizar a utilização do documento pela melhora no acesso ao seu conteúdo, dando-Ihe uma melhor contextualização. Por extensão, Documentarizar seria dar um status a um texto, gerar um "documento".

A gênese do processo de documentação remonta o final do século XIX, a partir do aumento da produção bibliográfica, da pesquisa científica e do surgimento de novos suportes. São fatores que originaram o desenvolvimento de novas técnicas para a organização e a administração da informação. A Bibliografia, que até então se dedicava a essa organização, não dava mais conta das novas demandas. Para Otlet (1997), a documentação surge concomitante às atividades da biblioteca pública e das práticas documentais, apresentando o diferencial de "acompanhar o documento desde o instante em que ele surgia da pena do autor até o momento em que impressionava o cérebro do leitor" (OTLET, 1997, p. 115)².

Para exemplificar uma relação entre o digital e o social, Salaün (2007a) traçou um paralelo entre o papel do documento impresso no surgimento das sociedades modernas e do

\footnotetext{
2 Otlet propõe o uso da palavra "documento", considerando um teor mais abrangente, como forma de não limitar seu conceito a uma tipologia. O "documento" poderia representar algo em que o conhecimento pudesse ser registrado e do qual se observe alguma propriedade informativa.
} 
documento digital, junto à mudança social que estamos vivenciando. Isso é o que chama de "documentarisation". Traduzindo, a documentarização acompanha a industrialização, o estabelecimento do Estado, no sentido moderno, ou, entre muitas outras ilustrações possíveis, a ascensão da ciência positivista. Paul Otlet, e sua tentativa de fundar uma "documentação", no início do século XX, é figura emblemática da necessidade de racionalizar a proliferação documentária que presenciamos hoje.

A ideia de Redocumentarizar, para Pedaúque (2003), teria surgido a partir de uma necessidade plural e a de redimensionar as práticas documentais com o advento das tecnologias digitais no final do século XX e início do século XXI. A partir daquele momento observa-se uma mudança na perspectiva do modo de se encarar o documento, influenciada pela explosão digital e a necessária caminhada da Documentarização para a denominada Redocumentarização.

Michel (2000) aponta as principais características que ele considera para o documento digital, como a sua facilidade de armazenamento, localização e recuperação; a flexibilidade do seu formato; a disponibilidade instantânea à distância e a possibilidade de relacionar-se com outros documentos como um hiperdocumento, aproximando-se de uma complementariedade hipertextual ${ }^{3}$. Em comparação ao documento tradicional, esse autor aponta que o documento digital conseguiria refletir as necessidades de comunicação humana, funcionando como um vetor de expressão de sentido, mais aberto e universal que o documento tradicional.

Na Web 2.0, ou apenas em sites dinâmicos, a estabilidade dos documentos clássicos desaparece frente à Redocumentarização e assume outra dimensão. A estabilidade da mídia foi substituída por estruturas em formatos de arquivo que separaram o conteúdo do seu formato. O digital mudou a questão do suporte do documento para o problema da sua estrutura.

O documento digital teria se tornado uma Entidade regida pelas leis da quantidade expressiva, por seu conteúdo estar relacionado com um número quase infinito de seres e ser potencialmente visível para um número interminável de leitores. Por possuir um caráter ativo, parece ser inviável tratar a informação na Web por meio de modelos de tratamento da informação totalmente tradicionais. Cotte (2008), considerando os estudos da

\footnotetext{
${ }^{3}$ É importante informar a respeito do documento digital e sua diferença em relação à ideia de documento hipertextual. Lamarca Lapuente (2009) comenta tal diferença dizendo que há uma confusão terminológica, pois muitos consideram documento digital como sinônimo de documento hipertextual. Porém, enquanto o primeiro possui um caráter mais genérico, correspondendo tecnicamente a um registro de bytes num computador, podendo estar na Web ou ser acessado remotamente; o documento hipertextual é digital, por conta do meio físico em que se manifesta, mas seu modelo de organização e relação informacional é particular, pois forma uma rede multisequencial de hipertextos podendo estar, também, na Web ou apenas ser acessado remotamente.
} 
Redocumentarização e a proximidade entre informação e documento, ressaltou a importância do documento virtual no âmbito de um sistema de recuperação da informação. $O$ autor conclui que a informação, cada vez mais flexível e fluída, determina que a materialidade do documento não se fixe em apenas um tipo de suporte.

O processo de Redocumentarização é considerado como uma "imposição" do universo digital, versando sobre "tratar novamente um documento ou uma coleção de documentos rearticulando os conteúdos segundo o uso ou a interpretação do usuário" (ARNAUD \& MERZEAU, 2009, p. 186). O seu ciclo passa por uma série de procedimentos, objetivando transpor o documento tradicional para o meio digital (SALAÜN, 2007b). Considera-se esse processo como outra ordem documentária, que seria definida a partir de sua relação com os dispositivos existentes em diferentes sociedades e épocas. Durante a caminhada de desenvolvimento desta pesquisa, o processo de Redocumentarização foi frequentemente confundido com o de Reformatação de acervos. Deduzimos que se trata de dois elementos distintos, sendo a reformatação servindo de base para uma posterior Redocumentarização no âmbito arquivístico.

A digitalização, e/ou até a digitação, para a geração de bancos de dados de acesso virtual se baseia na Reformatação de Acervos, ou seja, na transposição do conteúdo informacional dos documentos em um suporte para outro suporte. No caso da digitalização, pode acontecer por meio de um escâner, realizando a captação de um documento em suporte papel o transformando em informações lógicas que serão acessadas por dispositivos informáticos. Tal processo, a Reformatação de Acervos, pode ser realizado também para o meio analógico, como é o caso da microfilmagem. Ainda, a mesma informação migrada para o microfilme permite sua posterior digitalização, evitando o uso do escâner tradicional sobre o papel, considerando-se, nesse caso, os documentos arquivísticos. Dessa maneira, nesta pesquisa buscamos compreender que Reformatação de acervos é um procedimento técnico de migração de suporte documental. Já a Redocumentarização, por nós estudada, diz respeito ao processo de organização em meio digital de uma documentação reformatada, seguindo os princípios clássicos da Arquivologia.

Às preocupações científicas dos arquivistas se somou a inerente preservação dos documentos eletrônicos: digitalizados e também os nato-digitais ${ }^{4}$. Os acervos compostos por

4 O Art. 20 do Decreto n. 8.539 , de 8 de outubro de 2015, considera as seguintes definições: “I documento - unidade de registro de informações, independentemente do formato, do suporte ou da natureza; II - documento digital - informação registrada, codificada em dígitos binários, acessível e interpretável por meio de sistema computacional, podendo ser: a) documento nato-digital - documento criado originariamente em meio eletrônico; ou b) documento digitalizado - documento obtido a partir da conversão de um documento não digital, gerando uma fiel representação em código digital. 
documentos eletrônicos, além dos muitos benefícios que proporcionam, estabelecem cuidados de preservação mais delicados, vulneráveis e rigorosos do que os adotados para os acervos físicos e analógicos ${ }^{5}$. O processo de reformatação envolve não apenas a duplicação da informação, mas a geração de um novo tipo de acervo com características físicas diferentes do original, mantendo-se ainda a preservação e conservação dos originais. Assim, o que ocorre é que o processo de Redocumentarização - mais adiante definiremos o de específico interesse da nossa pesquisa -, é viabilizado após a reformatação dos acervos, migrando a documentação para o meio digital por meio do processo de digitalização.

Para definir o conceito de Redocumentarização, Salaün (2007b) prefere se basear na noção de Documentarizar. Para o autor, a ideia de Redocumentarizar traz o mesmo objetivo que Documentarizar, apenas se diferenciando na possibilidade de rearticular os conteúdos de forma mais dinâmica, principalmente em função do auxílio da tecnologia digital. A partir desse entendimento, o autor afirma que o contexto digital teria se tornado a oportunidade para $\mathrm{o}$ desenvolvimento da Redocumentarização.

Salaün (2006) pretendeu mostrar, em parte do seu artigo S'inspirer de Roger T. Pédauque, como o trabalho de todos os contribuintes dos textos produzidos pelo coletivo de autores Roger T. Pédauque é rico. Ele considera que aqueles autores semearam ideias para o futuro, e que cada leitor encontraria um material para desenvolver e expandir a sua própria reflexão. Salaün (2006) discorreu sobre o terceiro e último capítulo do livro de Roger T. Pédauque, destacando o conceito de "redocumentarisation", com ênfase na relação entre a transformação documentária com a mudança social. Mas, para Salaün (2006), a ideia de Redocumentarização é construída sobre um paradoxo, que chama de "O paradoxo de Roger". Afirma que a Web promove, conjuntamente, dois movimentos opostos: o desenvolvimento de intercâmbios espontâneos (conversas) e a sua fixação pública e documentada. Em outras palavras, a Web transforma automaticamente o íntimo e efêmero em documento. Para o autor, o reconhecimento desse paradoxo iluminaria o processo de Redocumentarização. No entanto, não o especificamente trabalhado, estudado e verificado pela presente pesquisa. Pois, trabalhamos com uma concepção de Redocumentarização pertinente aos procedimentos arquivísticos. Tais considerações, de Salaün (2006), se enquadram mais intimamente aos exemplos que apresentaremos a seguir, com os quais buscamos ilustrar as variadas formas de reapropriação que encontramos para o termo Redocumentarização.

No caso anteriormente descrito, "O paradoxo de Roger", não se trataria simplesmente de uma questão de estratégias resultantes de interesses industriais ou de grupos de

\footnotetext{
${ }^{5} \mathrm{O}$ microfilme, formato analógico, tem estimativa de durabilidade de 500 anos.
} 
entusiastas, mas, sim, de um movimento estrutural proveniente de uma arquitetura de rede que vai além da vontade dos atores envolvidos. Usam-se os recursos da Redocumentarização, organizando-os e dando-Ihes um sentido em sua própria dinâmica. Admitir isso é conhecer a importância do fenômeno e estar ciente da urgência de sua análise e controle para evitar equívocos (SALAÜN, 2006). Entendemos tratar-se de uma continuidade histórica na qual, é importante notar, os profissionais de documentação assumem compulsoriamente um papel mais importante nos dias de hoje porque novas habilidades se tornaram essenciais.

Para Salaün (2007b), a documentarização está claramente presente nas quatro idades do documento, entre a segunda e a terceira ${ }^{6}$. A Redocumentarização marca, assim, a transição da terceira para a quarta. Essas idades acompanham diferentes organizações ideológicas e sociais. Salaün (2007b) as resume no quadro 1.

Quadro 1 - As duas escalas documentais. Traduzido e adaptado de Salaün (2007b).

\begin{tabular}{|l|l|l|}
\hline & Documentarização & Redocumentarização \\
\hline Datas (períodos) & XIX e XX & XX e XXI \\
\hline $\begin{array}{l}\text { Alguns números } \\
\text { Quelques figures) }\end{array}$ & $\begin{array}{l}\text { M. Dewey, Paul Otlet, O. } \\
\text { Lafontaine, W. Carnegie. }\end{array}$ & $\begin{array}{l}\text { Tim Berners-Lee, T. Nelson, Bill } \\
\text { Gates, S. Brin. }\end{array}$ \\
\hline Técnicas & $\begin{array}{l}\text { Classificação, indexação, } \\
\text { linguagens documentárias, } \\
\text { Thesaurus. }\end{array}$ & $\begin{array}{l}\text { Protocolos da Web (HTML, URL) } \\
\text { Web 2.0, Web Semântica, } \\
\text { Ontologias. }\end{array}$ \\
\hline Realizadores (entidades) & Redes de Bibliotecas do Mundo. & \begin{tabular}{l} 
Google, Wikipédia. \\
\hline Modernização
\end{tabular} \\
$\begin{array}{l}\text { O espírito científico, a lógica, a } \\
\text { razão, o Estado-nação, votos, a } \\
\text { indústria, o autor. }\end{array}$ & $\begin{array}{l}\text { Conhecimento limitado, razão- } \\
\text { estatísticas, os indivíduos, as } \\
\text { opiniões, os serviços, a } \\
\text { reflexividade. }\end{array}$ \\
\hline $\begin{array}{l}\text { Alguns dos objetos documentais } \\
\text { em questão. }\end{array}$ & $\begin{array}{l}\text { Revistas, regulamentos, } \\
\text { contratos, patentes, obras, } \\
\text { mídia e impressão. }\end{array}$ & $\begin{array}{l}\text { Pré-publicações, formulários, de } \\
\text { código aberto, wikis, blogs e a } \\
\text { própria Web (sua navegação). }\end{array}$ \\
\hline
\end{tabular}

Fonte: Salaün, 2007b.

Para Pédauque, a Redocumentarização toma um sentido mais amplo. Para o coletivo de autores, seria uma nova forma de documentarização, que reflete, ou tenta refletir, uma organização pós-moderna de nosso relacionamento com o mundo, encontrada tanto no setor privado quanto no coletivo e público. Como na modernização anterior, os documentos envolvidos no processo desempenham um papel-chave.

\footnotetext{
${ }^{6}$ Teoria das quatro idades considerada por Salaün (2007b): corrente, central, intermediário e permanente (LODOLINI, 1995 apud NÚÑEZ-FERNÁNDEZ, 1999). A teoria das quatro idades documentais é uma proposta do arquivista italiano Elio Lodolini. Seu objetivo seria o de dividir a fase intermediária em duas etapas, como forma de otimizar a operacionalização dos documentos da idade intermediária.
} 
2.1 Um processo de Redocumentarização do mundo: formas e reapropriações mapeadas pela pesquisa

\subsection{1 "Redocumentação" dos vestígios da atividade mediada por computador}

Para Yahiaoui, Prié e Boufaida (2008), o documento impresso passou por uma evolução significativa ao longo do tempo, marcado por quatro fundamentos: a idade do livro, a idade da prensa, a idade da documentação e, finalmente, a idade dos arquivos digitais.

Citando Salaün (2007b), Yahiaoui, Prié e Boufaida (2008), consideram a Redocumentarização o surgimento de uma nova ordem documentária, melhorando a apresentação e a legibilidade do documento e dando-Ihe uma legitimidade que excede o uso local ou imediato. Trataria, dessa maneira, de uma nova atividade no contexto digital.

Apesar de partir das teorias que descrevem o procedimento de Redocumentarização, esses autores dizem estar interessados em um processo de "redocumentation" (redocumentação) da atividade mediada por computador ${ }^{7}$. Descrevem esse processo como a recuperação, em um novo conteúdo documentário, dos traços gerados automaticamente por meio da interação do usuário com o sistema do computador. Quando um sistema de computador entra em funcionamento, geralmente recolhe extensos dados sobre a sua utilização. Sua instrumentalização, por um módulo de rastreamento, permite observar e registrar a interação do usuário com a máquina durante a sua atividade.

Esses traços, nomeados de sources de traçage, traduzido por nós como "fontes de rastreamento", são gerados em diferentes formatos (arquivos de log, arquivos XML estruturados, captura de tela, gravação de vídeo ou áudio, etc.). Podem ser usados para descrever a atividade mediada por computador e, desse modo, formar uma primeira documentação dessa atividade. $O$ documento proveniente desse processo é considerado, por esses autores, como o mais apropriado para se descrevê-la em toda a sua riqueza.

A ideia, aqui, seria a integração, sob um processo documentário, que forma o conteúdo de vestígios de navegação, além de disponibilizar alguns elementos que podem traçar o perfil do usuário. Ainda, facilitar a sua transmissão a outros sujeitos ou sistemas para que gerem interpretações. E, complementamos: possibilita, ainda, realizar inferências e acarretar em interoperabilidade.

Trata-se de um tema do contexto da engenharia do conhecimento, uma Redocumentação dos vestígios (concebido como uma primeira documentação das atividades).

\footnotetext{
7 Dans ce contexte, il nous semble pertinent de nous intéresser à la redocumentation de l'activité médiée informatiquement, que nous définissons comme la reprise au sein d'un nouveau document du contenu des traces générées de façon automatique suite à l'interaction de l'utilisateur avec le système informatique (YAHIAOUI, PRIÉ E BOUFAIDA, 2008, p. 2).
} 
Considera-se que tal atividade oferece a oportunidade de enriquecer o seu conteúdo a partir do conhecimento proveniente do contexto da sua produção (contexto da atividade desempenhada e processo cognitivo de rastreamento do usuário).

Para refletir sobre o que nomearam de "Redocumentação da atividade mediada por computador", por meio de uma redocumentação dos traços gerados nessa atividade, Yahiaoui, Prié e Boufaida (2008) optam pelo contexto da transactions communicationnelles (teoria das operações comunicativas), proposto por Zacklad $(2003)^{8}$. Os autores buscam se fundamentar no quadro dos elementos conceituais usados atualmente no campo documental tais como o processo de "Documentação", "Documentarização" e "Redocumentarização" ${ }^{9}$, qualificando-os como processos semelhantes à sua proposta de Redocumentação. Em seu artigo, apresentam um estudo detalhado de cada um desses conceitos, apontando o que consideraram ser lacunas em relação ao seu objetivo ${ }^{10}$.

Para os autores, Documentarizar é tratar novamente um documento ou uma coleção destes, permitindo rearticular o conteúdo semiótico na sua interpretação e seus usos, por exemplo: organizar uma coleção de acordo com uma nova lógica de associação. Como no caso da Documentarização, a Redocumentarização estaria relacionada a um problema de acesso e de formato. No entanto, esse acesso seria mais subjetivo, em oposição à Documentarização, cujo acesso primário possivelmente seja mais objetivo. Consideram tratar-se de uma transação comunicativo simbólica, o que resulta na rearticulação do conteúdo de uma produção semiótica inicial (conteúdo dos documentos originais).

Da mesma forma que crescentemente nos inquietava, à medida que avançávamos no estudo do tema Redocumentarização, também esses autores apontam a necessidade de se saber se o resultado do processo acarreta sempre na mesma entidade. No entanto, não apresentaram uma conclusão em seu estudo, da mesma forma que entendemos ser necessária uma reflexão vertical sobre o fato. Para esses autores, o significado de um documento enriquecido com comentários pode desviar-se muito do significado do documento original. Eis aí, inclusive, uma dimensão de forte diferenciação entre a Redocumentarização e a Arquivística. A intervenção e alteração do documento de arquivo original constitui, do ponto

\footnotetext{
8 Articulando diferentes dimensões envolvidas na caracterização de operações comunicacionais, propõe categorizações de atividades coletivas. Origina-se, em parte, da confluência de três disciplinas: ciência cognitiva representada, pesquisa em organizações científicas e de gestão, particularmente influenciada pelos trabalhos de $\mathrm{H}$. Mintzberg e A. Hatchuel e a pesquisa em psicologia social de interações.

9 “Documentation, de documentarisation, de redocumentarisation" (YAHIAOUI; PRIÉ; BOUFAIDA, 2008, p. 2).

${ }^{10}$ Os autores dissertam sobre os vestígios de atividade de redocumentação, a teoria das operações comunicacionais, traços resultantes da atividade de documentação e vestígios da documentarização. Esses elementos são secundários no objetivo desta pesquisa. Assim, estamos focando na relação direta desses autores com o processo de Redocumentarização.
} 
de vista arquivístico, uma fraude, uma deliberada falsificação do documento original. Por exemplo, uma intervenção em uma escritura de imóvel consiste em crime passível de prisão.

Para os autores, o significado de um documento enriquecido com comentários pode desviar-se muito do significado do documento original. No entanto, consideram que, no documento redocumentado o valor de evidência intrínseca permanecerá, mesmo que haja sucessivas intervenções, enriquecendo-o quantitativamente (adição de fontes e referências) e qualitativamente (adição de comentários).

Para Yahiaoui, Prié e Boufaida (2008) a Redocumentarização pode ser realizada por uma pessoa ou por outras pessoas, como parte de rearticular um conteúdo por um ponto de vista pessoal. Já a Redocumentação, os autores definem como uma atividade do contexto digital, pelo fato de criar um novo documento digital, descrevendo-o a partir de documentos existentes. A Redocumentação teria o fim de reorganizar o conteúdo dos documentos originais para filtrar (remover partes desnecessárias), acrescentar informações sobre o contexto de sua produção ou de outras fontes externas de informação.

Diferiria, assim, da Redocumentarização, pela possibilidade de reformular completamente o conteúdo dos documentos iniciais (reescrever no sentido amplo), para apresentá-los de forma diferente e interpretá-los de forma explícita para um novo documento integral (em oposição a um documento enriquecido). A atividade de Redocumentação é realizada no âmbito de uma operação de comunicação simbólica entre uma pessoa e, possivelmente, em grupo, dando origem a uma nova semiótica registrada em um suporte duradouro (um novo documento).

Os autores propõem que dois processos podem melhorar a qualidade da documentação digital, reforçando o estatuto de provas documentais. Primeiro, o traço produzido pela Documentarização, baseado na exploração dos seus suportes para facilitar o acesso ao conteúdo de acordo com uma dimensão interna e externa (catalogação, indexação, formatação, etc.). Segundo a Redocumentarização, que ofereceria mais liberdade para rearticular o conteúdo de vestígios, de acordo com a sua interpretação e necessidade de usos, preservando o valor probatório desses traços sem produzir novos documentos. Relembremos que os autores se referem a documentos nato digitais e não propriamente ao nosso foco de pesquisas, o documento digitalizado. Mas, ainda, consideram esses dois processos insuficientes para as suas necessidades próprias. Propõem, então, o conceito de redocumentation des traces, por nós traduzido como "Redocumentação dos Vestígios", conforme o referencial teórico das operações comunicativas. Durante tal processo, um usuário interpreta e reescreve os rastros de um novo documento, o que corresponderá a um determinado gênero. Esse documento pode descrever a atividade em toda a sua riqueza, pois 
é possível reformular o conteúdo de vestígios enriquecendo-o com outras informações (comentário, anotação, justificação ou informação de contexto), apagar partes ou reescrevêlo inteiramente. Esse documento fortalece o status do resultado documentário em três dimensões: legibilidade, compreensibilidade e troca.

Assim, embora essas noções, em absoluto, não digam respeito ao valor primário do documento de arquivo, a Redocumentação, proposta pelos autores, poderia ter uso em outros campos: a) uma documentação da atividade por meio da criação de um novo documento que a descreve; b) traços da documentarização, permitindo melhor acesso (indexação, etc.) e c) uma Redocumentarização através da rearticulação do seu conteúdo, de acordo com a visão de novos usuários. E, este último item, é passível de aplicação do contexto da arquivologia. Também entendemos que é possível que, no processo de digitalização dos acervos arquivísticos de idade permanente, seja útil a aplicação da "documentação da atividade por meio da criação de um novo documento que a descreve", nos informando sobre acessos realizados à derivada digital do documento original de um arquivo permanente disponibilizado virtualmente.

Yahiaoui, Prié e Boufaida (2008) consideram que esse processo seria o efeito de uma nova modernidade, impulsionado por desenvolvimentos recentes na tecnologia e redes sociais virtuais, no qual a opinião e a criatividade dominam a oferta digital de novas oportunidades, apropriando-se dos documentos existentes para atender aos interesses das novas demandas de uso, intepretação e reapropriação de antigas instâncias.

\subsubsection{Redocumentarização: web, texto e conversação}

Salaün (2008) infere que a Web tem perturbado a ordem tradicional dos documentos, aparecendo como uma nova mídia, tomando seu lugar entre as mais tradicionais. O processo documentário pela Web desafia a ordem como uma nova mídia. Normalmente, mesmo diante de novas ferramentas, pesquisadores trabalham dentro do velho mundo dos documentos. No entanto, têm uma responsabilidade especial na construção dos novos formatos. A evolução dos formatos digitais autoriza transposições midiáticas cada vez mais heterogéneas e enfraquece a antiga robustez documentária. Propõem uma outra organização, a partir do desenvolvimento das redes e do advento da Web. Ocorreria, assim, uma junção dos arquivos com os textos suscitando mudanças contínuas, acarretando transformação da sua natureza documentária.

A navegação na web se tornou estruturada pela dinâmica dos motores de busca. Os modos de leitura nesse meio são muito diferentes dos realizados em papel. Os motores de busca usam, principalmente, ferramentas linguísticas e estatísticas. O estudo, encomendado 
pela Biblioteca Britânica, mostrou que $60 \%$ dos usuários de periódicos científicos eletrônicos não acessam mais de três páginas e a grande maioria nunca retorna. Sem dúvida, alguns itens são baixados, mas não há nenhuma evidência de leitura. Os usuários da Internet passariam a maior parte do seu tempo procurando um caminho, muito mais do que olhando para o que encontraram durante o percurso. Além disso, o tempo médio gasto em livros eletrônicos e sites de revistas é muito curto, respectivamente, 4 e 8 minutos (SALAÜN, 2008). UCL (2008 apud SALAÜN, 2008, p. 2) destaca:

É claro que os usuários não estão lendo on-line, no sentido tradicional. Há de fato sinais claros de que novas formas de "leitura" apareçam acompanhando os ganhos rápidos do "poder da navegação" da Internet através de títulos, páginas de conteúdo e resumos. Quase se poderia dizer que eles vão em linha para evitar a leitura no sentido tradicional do termo ${ }^{11}$ [tradução nossa].

As consequências são, provavelmente, muito importantes para os pesquisadores que precisam fazer novas perguntas sobre os materiais que analisam, porque estes podem ter perdido o status implícito que carregavam antes. O objeto foi alterado em sua natureza, e a indagação principal é saber se é adequado analisá-lo como se nada tivesse mudado. De modo mais geral, as consequências também são muito importantes para toda a nossa relação com o conhecimento registrado e, talvez, até mesmo sobre o conjunto de relações sociais, quando se refere ao papel regulador geral da Literatura.

Implicitamente, considera-se a Web como uma grande, global e permanente conversação. Os atores que a dominam a consideram como o texto de uma grande conversa global e ininterrupta. Nesse processo, Salaün (2008) pergunta se os usuários não têm, na verdade, iniciado uma conversa com a sua máquina ou de todo o sistema de representação a que a máquina fornece acesso ${ }^{12}$. Para o autor é essencial tentar entender a dimensão documental dos movimentos em curso, pois, no geral, estamos presenciando um movimento massivo e desordenado de "redocumentarisation", sobre o qual seria difícil prever resultados.

A cada vez que se propõe a pensar, devido às mudanças intensas, desestabilizam-se as tentativas de explicação. Os esforços lançados por Tim Berners-Lee para uma Web Semântica (BERNERS-LEE; HENDLER \& LASSILA, 2001), em seguida, para uma ciência da Web, podem ser compreendidos dessa forma. Mas, um número muito grande de outros atores e outras lógicas ajudam a interferir também nessa instabilidade. Ferramentas desenvolvidas por

\footnotetext{
11 II est clair que les internautes ne lisent pas en ligne dans le sens traditionnel du terme. II y a en effet des signes manifestes que de nouvelles façons de "lire» apparaissent accompagnant les gains rapides de la "puissance de navigation" des internautes au travers des titres, du contenu des pages et des résumés. On pourrait presque dire qu'ils vont en ligne pour éviter de lire au sens traditionnel du terme.

12 On peut se demander si les internautes n'ont pas en fait engagé une conversation avec leur machine ou l'ensemble du système de représentation auquel elle donne accès (SALAÜN, 2008, p. 2).
} 
cientistas da computação estão no centro desse movimento. Salaün (2008) alerta que talvez seja hora de se questionar seriamente a importância do conceito de estrutura do documento.

\subsubsection{O Projeto The Commons Photos Normandie: um projeto coletivo de valorização dos} fundos patrimoniais

O benefício do compartilhamento colaborativo proporcionado pela Web 2.0 tem permitido o surgimento de novos modos de processamento da informação. O projeto em análise está considerando a existência de um "campo da Redocumentarização fotográfica"13, em que diferentes práticas têm surgido frequentemente, demonstrando uma rápida renovação dos modos e práticas dos chamados "usuários documentadores" ${ }^{14}$, bem como a reapropriação de ferramentas de processamento (PECCATTE, 2008). No entanto, a partir das nossas análises e entendimentos de o que se trata ser um processo de Redocumentarização completo e destinado ao tratamento arquivístico de um acervo documental, esse projeto nos parece uma reformatação de acervo fotográfico.

O projeto The Commons Photos Normandie visa melhorar a indexação de um fundo de fotos históricas da Batalha da Normandia, ocorrida de junho a agosto de 1944, durante a Segunda Guerra Mundial. Com propósito de trabalho colaborativo, o projeto está ativo desde janeiro do ano de 2007, e utiliza a plataforma Flickr ${ }^{15}$ para compartilhar fotos e vídeos.

As fotos do site Archives Normandie ${ }^{16}$ são provenientes dos Arquivos Nacionais dos Estados Unidos e do Canadá, e são declaradas como livres de direitos autorais. O Flickr aparece, nesse projeto, apenas como uma ferramenta integrada com outras aplicações Web, como fóruns e fontes de informação, além da realização de intenso trabalho de pesquisa.

Nesse projeto, o processo de que denominam por Redocumentarização é um empreendimento coletivo, que tem por objetivo reprocessar uma coleção de documentos fotográficos. Ou, reindexar um corpus iconográfico com as possibilidades oferecidas pelas tecnologias digitais e da Internet como um todo.

A experiência adquirida com esse projeto, como relatam, é muito positiva e certamente aplicável a muitas áreas que requeiram a participação de especialistas espalhados

\footnotetext{
13 Le domaine de la redocumentarisation de fonds photographiques (PECCATTE, 2008, p. 01).

${ }^{14}$ Acteurs documentaires.

15 O Flickr é um site de compartilhamento de fotos e vídeos. Em sua funcionalidade básica, o armazenamento é gratuito. Recursos não limitados cobram uma anuidade. 0 site oferece o armazenamento privado ou público de imagens. O Flickr foi desenvolvido pela empresa canadense Ludicorp, em 2002, e adquirido pelo Yahoo! em 2005. 0 site atualmente possui mais de 2 bilhões de fotos.

16 O site Archives Normandie (1939-1945) é um serviço público do Conselho Regional de Basse, Normandia, criado em 2004 por ocasião da comemoração do sexagésimo aniversário da libertação da Normandia. Esse site possui mais de 13 mil fotos sobre a ocupação, libertação e Reconstrução da região (http://archive.is/www.archivesnormandie39-45.org).
} 
em todo o mundo. Peccatte (2008) cita nesses moldes, como mais um exemplo da possibilidade de um trabalho colaborativo amplo, a reunião de um grupo de especialistas em numismática para a criação de uma coleção de fotos de moedas antigas ${ }^{17}$.

Iniciativas como o The Commons Photos Normandie abrem novas perspectivas na valorização dos fundos patrimoniais - e, provavelmente, para além dessa área. Representa, ainda, parte de um movimento de surgimento de novas mídias, no qual os metadados descritivos não são fixos, mas proporcionam uma melhoria real do conteúdo público. Nesse processo, os metadados são, definitivamente, mais considerados como fichas técnicas estáticas. $O$ processo permanece evoluindo de acordo com a dinâmica de colaboração.

Ao incluir os metadados necessários para a reconfiguração, os documentos ganham rastreabilidade, uma característica que vem sendo atribuída ao processo de Redocumentarização, como descrevemos anteriormente ao descrevermos o processo de Redocumentação proposto por Yahiaoui, Prié e Boufaida (2008). Os documentos tradicionais, em sua transposição, adquirem a plasticidade dos documentos nativamente digitais e podem desfrutar das possibilidades dessa nova dimensão.

Tecnologias para indexação profissional existem para trabalhos individuais ou para a produção profissional, mas não é, segundo Peccatte (2008), um contexto colaborativo. Para esse autor, é possível ir além da possibilidade de indexação social permitida pelo Flickr, definindo uma verdadeira plataforma colaborativa, facilitando o trabalho dos profissionais envolvidos com a Redocumentarização de vários fundos iconográficos, com total controle documentário e do seu processo editorial.

\subsubsection{Redocumentarização no contexto da arquivologia e das fontes de informação da pesquisa historiográfica}

Diante dos contextos e abordagens anteriormente descritos, referentes ao processo de Redocumentarização, ou das possibilidades destes, definimos que à nossa pesquisa não interessava estudar, especificamente, um processo de Redocumentarização no "campo da Redocumentarização fotográfica"18, exatamente como nos moldes operados por Pecatte (2008), lembrando que não o consideramos assim, como já comentamos. Também, não estava no escopo da tese uma "Redocumentação" da atividade mediada por computador, como proposta por Yahiaoui, Prié e Boufaida (2008). Como apresentado anteriormente, esta

\footnotetext{
17 O grupo envolvido com o projeto The Commons PhotosNormandie tem a pretensão de materializar esse projeto de numismática, porém, até o momento da publicação do artigo de Peccatte (2008), eles não haviam conseguido reunir os profissionais necessários para tal empreendimento.

${ }^{18}$ Nos referimos aqui ao Projeto The Commons Photos Normandie.
} 
"Redocumentação" derivaria da Redocumentarização e seus processos, a partir das concepções de Salaün (2007b), e explora, ainda, o contexto da Transactions Communicationnelles (teoria das operações comunicativas), proposto por Zacklad (2003).

Nosso objetivo de investigação se aproximava muito especificamente da exposta por Salaün (2008), e suas concepções a respeito da evolução dos formatos digitais, que, segundo o autor, autorizam transposições midiáticas cada vez mais heterogêneas. Mas não caminhamos na direção de discutir o tema do enfraquecimento da antiga robustez documentária, que, ainda conforme o autor, deriva de uma outra organização, suscitada pelo desenvolvimento das redes e da "explosão" da Web. Como visto, ocorreria, nesse caso, uma junção dos arquivos e os textos, suscitando mudanças contínuas, acarretando na transformação da natureza documentária.

$\mathrm{Na}$ fundamentação teórica sobre o tema Redocumentarização, buscamos caminhar dentro dos princípios fundamentais propostos pelo coletivo Roger T. Pédauque (2007), vistos, revistos e expressivamente analisados, principalmente, por Michel Salaün (2006, 2007a, 2007b, 2008). Essa literatura científica encontra-se publicada praticamente e exclusivamente, na atualidade, em língua francesa. Nossa pesquisa bibliográfica compreendendo variados idiomas, especificamente buscando por textos que abordassem sobre o tema Redocumentarização ${ }^{19}$, reportou trabalhos que deram ênfase em tratar do conceito em si, ou da sua abordagem e aplicação, provenientes de artigos e livros publicados nesse idioma, nativos da França e do Canadá. Também importante é salientar que esse termo não consta, até o presente momento, nos principais dicionários de terminologia arquivística encontrados no Brasil ${ }^{20}$.

Nossa pesquisa caminhou balizada pela linha da digitalização de documentos de arquivo que atingiram a terceira idade de seu ciclo - documento, em um sentido bastante alargado desse conceito, como preconizado pelo movimento historiográfico dos Annales ${ }^{21}$. Ou seja, elegemos uma linha de condução que abarcou a transposição ou a migração da documentação de arquivos permanentes para o meio digital. Tal processo é costumeiramente realizado por meio da reformatação de acervos.

A definição de Redocumentarização por nós enfocada deriva do corolário das leituras, mais especificamente, de Arnaud \& Merzeau (2009) e Jean-Michel Salaün (2006, 2007a,

\footnotetext{
${ }^{19}$ Redocumentarização, Redocumentarización, Redocumentarization, Redocumentarisation, respectivamente português, espanhol, inglês e francês.

20 Dicionário Brasileiro de Terminologia Arquivística (ARQUIVO NACIONAL, 2005) e Dicionário de Terminologia Arquivística da Associação dos Arquivistas São Paulo (CAMARGO \& BELLOTTO, 1996).

${ }^{21}$ Movimento historiográfico nascido na França, mais precisamente nos anos 1920. A partir desse momento, a historiografia passou por amplas transformações metodológicas, em parte, por meio da incorporação de novas tipologias de fontes de informação.
} 
2007b, 2008). Um processo considerado como "imposição" do universo digital, partindo do procedimento de Documentarização, tratando novamente documentos e coleções, com a possibilidade de rearticular os conteúdos segundo o uso ou a interpretação do usuário em função das possibilidades tecnológicas informáticas. O que na nossa interpretação compreenderia, por exemplo, proporcionar a realização de pesquisas, via sistema de recuperação, por Assuntos tanto quanto por Contexto, em um mesmo arranjo.

Tal ciclo envolve uma série de procedimentos necessários para arranjar os documentos tradicionais, por meio da reformatação desses acervos, em meio digital. Procedimento que permite rearticular os conteúdos de forma mais dinâmica, em função do auxílio da tecnologia digital. O processo imediatamente anterior de Documentarização, presente nas quatro idades do documento, entre a segunda e a terceira, oferece a organização necessária para uma posterior Redocumentarização.

Dessa maneira, compreende a documentação que nos interessou refletir sobre qualquer material que assumiu a terceira idade dentro do ciclo documental, destinando-se à guarda permanente. Sejam documentos oficiais provenientes do suporte papel, documentos não oficiais, também provenientes do suporte papel, além de fotografias, livros e objetos tridimensionais depois de digitalizados ou, como se preferir, reformatados e então Redocumentarizados. Trata-se de uma ampla variedade de fontes documentais, como já dito anteriormente: "qualquer traço ou vestígio das coisas que o homem fez ou pensou, desde o seu surgimento sobre a Terra" (ROBINSON apud BURKE, 1997, p. 20).

Essa amplitude se conjuga com a noção de abordagem ampliada do documento de valor histórico, preconizada no começo do século XX pelo movimento dos Annales. Ainda, mais especificamente, essa noção ampliada das fontes de pesquisa se relaciona com os subsídios que permitem a construção da narrativa histórica da memória e cultura material.

Diante da amplitude diversificada que vem sendo apresentada, a abordagem do processo de Redocumentarização, o conceito possível de embasar a nossa discussão, como há pouco descrito, costuma ser apropriado por projetos que buscam a promoção do acesso e uso público da memória e do saber produzido historicamente. Listando alguns exemplos que foram considerados por outros pesquisadores como de Redocumentarização, podemos citar a Biblioteca Digital Universal, mantida pela United Nations Educational, Scientific and Cultural Organization (UNESCO), o Projeto Gutenberg ${ }^{22}$, Projeto Resgate ${ }^{23}$ e o Projeto Memórias

\footnotetext{
22 Projeto criado por Michael Hart, em 1971, considerado pioneiro na disponibilização de $e$-books na Internet.

${ }^{23}$ O Projeto Resgate possui documentação avulsa, códices e coleções de cartografia e iconografia relativas ao Brasil existente no Arquivo Histórico Ultramarino, catalogada, microfilmada e digitalizada. Disponível em: <http://www.cmd.unb.br/resgate_ahu.php>.
} 
Reveladas ${ }^{24}$. Tais projetos foram citados por alguns autores como se enquadrando no processo de Redocumentarização, mas a partir do nosso entendimento a respeito deste, não podemos afirmar que todos eles se enquadrariam na nossa visão desse processo, que é intimamente ligada ao contexto arquivístico.

De toda forma, esses projetos são desenvolvidos a partir de acordos nacionais e internacionais por meio da cooperação entre universidades, centros de pesquisa, bibliotecas e arquivos de diferentes países propiciando acesso à informação histórica de caráter público. Podemos citar, ainda, de iniciativa mais recente e em andamento, o convênio entre a Biblioteca Vaticana e a Bodleian Library, da Universidade de Oxford, que estabeleceram uma parceria para a realização de um plano de digitalização que pretende colocar na Internet milhares de documentos selecionados entre as obras mais frágeis e raras de seus respectivos acervos $^{25}$. Porém, dentro da nossa acurada busca em estudar o conceito de Redocumentarização, tendemos a considerar que a maior parte dos projetos anteriormente citados se enquadrariam mais em processos de reformatação de acervos do que propriamente de Redocumentarização.

Para entender de forma mais efetiva o processo de Redocumentarização e ajudar que este seja melhor e mais amplamente compreendido quanto ao seu conceito, consideramos importante nos ater a uma experiência existente e estudá-la em sua prática. Dentre poucas possibilidades encontradas, escolhemos uma iniciativa desenvolvida por arquivos que guardam documentação de caráter histórica pública na Espanha, o Portal de Archivos Españoles (PARES) ${ }^{26}$. Este é um projeto inovador de agrupamento on-line de acervos documentais de diversos arquivos geograficamente dispersos.

Portanto, na pesquisa da qual deriva o presente texto, escolhemos conhecer mais a fundo o projeto que julgamos melhor se enquadrar nos fundamentos conceituais do nosso estudo. Projeto que afirmamos estar de acordo com a nossa avaliação de um processo de Redocumentarização de acervos arquivísticos. Ao se realizar uma busca no portal por, por exemplo, o termo Brasil, determinando, ou não em qual arquivo se pretende pesquisar, o consulente obterá os documentos relacionados com a indicação de se tratar de uma unidade documental simples ou um fundo, listando classes intermediárias que lhe demonstrarão o

24 O Projeto Memórias Reveladas do Centro de Referência das lutas políticas no Brasil (1964-1985) é de responsabilidade da Casa Civil da Presidência da República e abriga informações sobre os fatos da história política brasileira recente. O projeto engloba uma Rede Nacional de Cooperação e Informações Arquivísticas, com a participação de inúmeras entidades públicas e privadas, que inclui arquivos, museus e centros de documentação. Disponível em: <http://www.arquivonacional.gov.br>.

25 Prevê a digitalização de uma seleção de manuscritos hebraicos e gregos, de incunábulos do século XV, além de alguns dos primeiros livros impressos, religiosos e profanos.

${ }^{26}$ http://pares.mcu.es/. 
documento em seu local de organização (Figura 1). O usuário fará uma pesquisa por assunto, mas muito provavelmente, ao se dirigir pessoalmente ao arquivo indicado, encontrará o documento físico intelectualmente organizado em seu contexto, como será indicado no Portal.

Figura 1 - Exemplo de busca pelo termo Brasil, no Archivo General de Indias. Unidade Estado, Portal PARES.

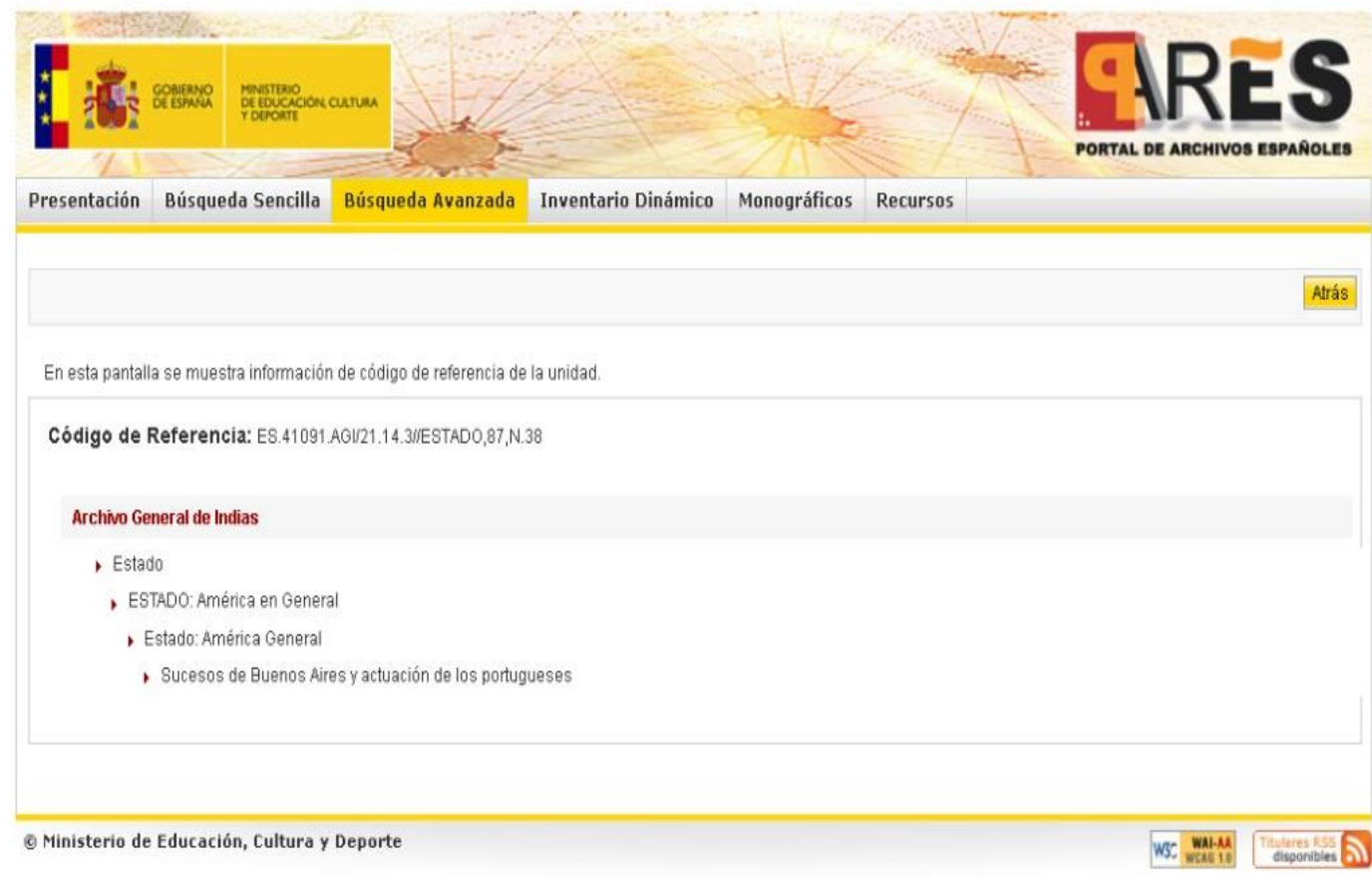

Em suma, consideramos o Portal PARES um excelente exemplo para nosso entendimento quanto ao processo de Redocumentarização no âmbito arquivístico. Esse projeto, abarca os fundamentos da Diplomática, da Arquivologia, da gestão de documentos e tecnologias da informação, como forma de fornecer um conjunto de requisitos que seja amplo, no tocante a proporcionar a melhor forma de disponibilização de acervos permanentes virtuais, seja por acesso remoto ou local. Consideramos o PARES um bom exemplo de como se manter a relação orgânica entre os documentos e garantir a confiabilidade, autenticidade e acesso aos documentos arquivísticos digitalizados. Seu sistema de funcionalidades é híbrido, gerenciando tanto de forma remota como local os documentos digitais e os convencionais das diversas unidades de informação públicas espanholas espalhadas pelas comunidades autônomas que compõem a Espanha.

\section{Considerações finais}

O processo de Redocumentarizar pode ser empregado como tratamento digital de documentos e coleções. É objeto de projetos que permitem a promoção do acesso e uso 
público da memória do saber produzido historicamente e de interesse da pesquisa científica. No entanto, nem todos os projetos que podemos encontrar espalhados pela Web se enquadram nesse método e acreditamos que muitos deles desconheçam tal conceito. Assim, praticam uma metodologia própria de reformatação de acervos, baseado nos princípios mais tradicionais da digitalização de documentos.

\section{Referências}

ARNAUD, Michel; MERZEAU, Louise (org.). Traçabilité et Réseaux Hermès. CNRS Éditions, Paris, n. 53, avril 2009.

ARQUIVO NACIONAL (Brasil). Dicionário brasileiro de terminologia arquivística. Rio de Janeiro: Arquivo Nacional, 2005.

BERNERS-LEE, Tim; HENDLER, James; LASSILA, Ora. The Semantic Web: A new form of Web content that is meaningful to computers will unleash a revolution of new possibilities. Scientific American, v. 284, n. 5, p. 34-43, May, 2001.

BURKE, Peter. A Escola dos Annales: 1929-1989: a revolução francesa da historiografia. São Paulo: UNESP, 1997.

CAMARGO, Ana Maria de Almeida; BELLOTTO, Heloisa Liberalli. Dicionário de terminologia arquivística. São Paulo: Associação dos Arquivistas Brasileiros, 1996.

COTTE, D. A La rencontre des objets "du numérique", I'occasion d'un nouveau paradigme pour les études de communication en organisation? Sciences de la Societé, n. 75, Oct. 2008.

INFORMATION behaviour of the researcher of the future. London: University College, Centre for Information Behaviour and the Evaluation of Research; British Library; Joint Information Systems Committee, 2008.

LAMARCA LAPUENTE, M. J. Hipertexto: el nuevo concepto de documento en la cultura de la imagen. 2009. Tese de doutorado (Fundamentos, Metodología y Aplicaciones de las Tecnologías Documentales y Procesamiento de la Información - Faculdad de Ciencias de la Información, Universidad Complutense de Madrid). Disponível em <http://www.hipertexto.info/> Acesso em 1 jan. 2013.

MICHEL, J., L'information et documentation. Un domaine d'activité professionnelle en mutation. Les Cahiers du Numérique, v. 1, n. 3, p. 47-64, 2000.

NÚÑEZ-FERNÁNDEZ, Eduardo. Organización y gestión de archivos. Asturias: Trea, 1999.

OTLET, P. El Tratado de Documentación: el libro sobre el libro: teoría y práctica. Murcia: Universidad de Murcia, 1997. 
OTLET, P. Traité de documentation: le livre sur le livre: théorie et pratique. Bruxelles: Mundaneum, 1934.

PECCATTE, Patrick. Une plate-forme sociale pour la redocumentarisation d'un fonds iconographique. Traitements et pratiques documentaires: vers un changement de paradigme? In: CONFÉRENCE DOCUMENT NUMÉRIQUE ET SOCIÉTÉ, 2008. Actes de la deuxième conférence. Paris: ADBS Éditions,2008. p. 373-389

PÉDAUQUE, R. Le document à la lunmière du numérique. Caen, France: C\&F, 2006.

PÉDAUQUE. R. Document: forme, signe et medium, le reformulations de numériques. STICCNRS, 8 jui., 2003. Disponível em: http://archivesic.ccsd.cnrs.fr/sic_00000511.html Acesso em 5 fev. 2013.

PÉDAUQUE. R. La redocumentarisation du monde (introduction: Comprendre et maîtriser la redocumentarisation). Tolouse: Cépaduès, 2007.

PÉDAUQUE. R. Le document à la lumière du numérique (Forme, texte, médium: comprendre le rôle du document numérique dans l'émergence d'une nouvelle modernité). Caen, France: C\&F, 2006.

SALAÜN, Jean-Michel. Introduction: Comprendre et maîtriser la redocumentarisation du monde. In La redocumentarisation du monde, sous la dir. de Roger T. Pédauque, 15-25. Toulouse: Cépadues Édition, 2007a.

SALAÜN, Jean-Michel. La redocumentarisation, un défi pour les sciences de l'information. Études de Communication, n. 30, Entre information et communication, Les nouveaux espaces du document, Université de Lille 3, décembre 2007b.

SALAÜN, Jean-Michel. La redocumentarisation, un défi pour les sciences de l'information. Études de Communication, n. 30, Octobre 2009. Disponível em http://edc.revues.org/index428.html Acesso em 5 fev. 2013.

SALAÜN, Jean-Michel. S'inspirer de Roger T. Pédauque. In: Le document à la lumière du numérique. Caen, France: C\&F Éditions, 2006. P. 17-23

SALAÜN, Jean-Michel. Web, texte, conversation et redocumentarisation. In: JOURNÉES INTERNATIONALES D'ANALYSE STATISTIQUE DES DONNÉES TEXTUELLES, 9., JADT, 2008.

SANTOS, Hercules Pimenta dos. Impactos provenientes da Redocumentarização de acervos permanentes na pesquisa histórica. Tese (doutorado) - Universidade Federal de Minas Gerais, Escola de Ciência da Informação, 2018. 290 f. 
SANTOS, Vanderlei Batista dos. A teoria arquivística a partir de 1898: em busca da consolidação, da reafirmação e da atualização de seus fundamentos. Tese (doutorado) - Universidade de Brasília, Faculdade de Ciência da Informação, Programa de Pós-Graduação em Ciência da Informação, 2011.

YAHIAOUI, Leila; PRIÉ, Yannick; BOUFAIDA, Zizette. Redocumentation des traces d'activité médiée informatiquement dans le cadre des transactions communicationnelles. In: JOURNÉES FRANCOPHONES D'INGÉNIERIE DES CONNAISSANCES, 19., IC'2008, Nancy, France, juin 18-20, 2008. p. 197-209.

ZACKLAD M. Transactions communicationnelles symboliques et communauté d'action: réflexions préliminaires. 2003. Disponível em: http://archivesic.ccsd.cnrs.fr/sic_00001122 Acesso em 12 dez. 2014. 